\title{
Health-care reforms and the pharmaceutical industry
}

\author{
Larry Botheras
}

As governments look ever more critically at the costs of drugs, those working in the pharmaceutical industry must become aware of the effects on their own career prospects.

IN a recent article (Nature 367, 764;1994) I dealt with the opportunities for career development for scientists in the pharmaceutical industry (including biotechnologists). The world is not ideal, however, and it is important to point out some of the (arguably short-term) pressures that are affecting employment prospects at present.

\section{Factors}

It almost goes without saying that government health-care budgets in most countries are under the strictest scrutiny, with the drug budget the principal target for cuts. In spite of the fact that spending on drugs represent a relatively small part of the overall cost of healthcare, the pharmaceutical industry is an easier opponent to take on than one of the more politically sensitive centres of cost. As a fairly secretive industry that has paid relatively little attention to expanding public knowledge of its activities, it has yet to fight back with any great effect.

There are also other factors that need to be considered. For example, the overall cost is becoming an increasingly important factor in drug registration. Already the Australian authorities require that a new product has proven cost benefits over the therapies already on the market . This approach is to be introduced in Canada as well, and the rest of the major markets are certain to follow suit. When one considers that new developments depend in the main on sophisticated high technology for their production, and are therefore expensive, the consequences of the pressure are obvious.

In addition, there is an increasing body of opinion which says that product licences should not be given to 'me too' products. Sad to say, many companies can be accused of excesses in this respect. What was the point, for example, of producing the $n$-th ACE inhibitor to join the market?

\section{Effects}

The overall effect of these changes has been to make the industry focus strongly on analysis of its business, and to develop its strategy in a way that will address its perceived strengths and weaknesses. Consequently, we are seeing some companies move out of some therapeutic areas which

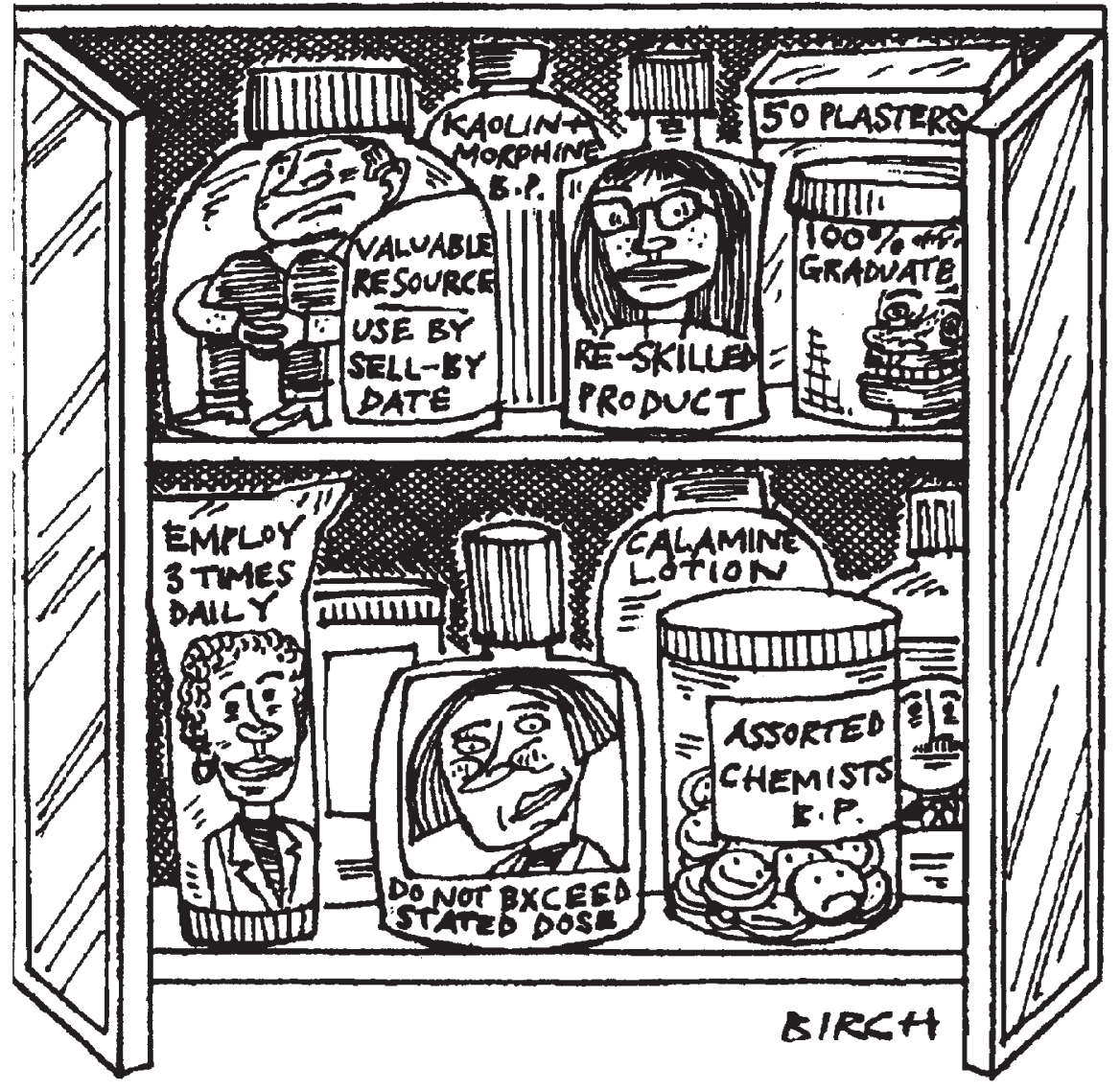

they no longer see as relevant to their present R\&D efforts, or which give an insufficient financial return. In tandem with this, several companies are analysing their internal 'skill set' and redefining the type of person they need to employ. This means that some companies are actually 're-skilling' - that is, making people redundant on the one hand and recruiting intensively on the other

\section{Employment prospects}

The principal advice to give, and not only to those working in basic research, is that they should cultivate at least some appreciation of the way in which these pressures affect their own positions. For example, it is no use at all being single-minded about discovering an excellent product that deals with a condition so rare as to affect only a small number of people. The prospect of recovering the company's investment must be small in these cases, given constraints on drug costs, and so the product has a limited future. Alternatively, a product may be directed at an established market, but have a manufacturing process so complex and a cost so high that it is impossible to imagine the product selling (probably in the face of a drug from a direct competitor which costs much less).

The future, therefore, will be one in which those who are successful have a sound understanding of why the corporation is in business and a propensity to adapt. It is to be hoped, too, that corporations will learn that they have to communicate their strategy successfully throughout the organization.

Larry Botheras is Head of Pharmaceuticals and Healthcare at Macmillan Davies, the executive search and selection consultancy based at Salisbury House, Bluecoats, Hertford, Herts, UK. 